\title{
Honoring Children's Ways of Knowing: A Story of Trust and Transformation in a Kindergarten Classroom
}

\author{
Keely D. Cline, Merlene Gilb, and Michelle Vaught
}

\begin{abstract}
This article spotlights the transformation of a kindergarten classroom culture as told through the story of selecting and naming a class pet, emphasizing the teacher's understanding of children's ways of knowing and the role of trust in building an inclusive and equitable classroom environment. Bronfenbrenner's bioecological systems theory serves as a lens in understanding the teacher's efforts to build a culture respectful of each individual child, the group as it formed, and class's identity in the broader learning community. The seemingly simple story is considered through the concept of rich normality, which recognizes the potential of everyday moments and experiences.
\end{abstract}

How much positive attention do we give to the ordinary moments in our programs for young children in North America? (Cooper, 2012, p. 299)

Rich normality has long been used as a metaphor by Reggio educators to describe the physical, social, emotional, and cognitive environments to which they continually aspire, calling attention to the promise of ordinary moments. For it is the stringing together of ordinary moments that ultimately gives shape and quality to human life over time. (Cutler \& McKillip, 2017, p. 25)

When Mrs. Vaught began her journey as a kindergarten teacher at a lab school, she did not foresee the transformational experiences awaiting her. On the first morning of kindergarten, some of the children in Mrs. Vaught's class shed a few tears as they watched their families leave. However, after the children went home in the afternoon, it was then Mrs. Vaught who shed a few tears, feeling she had made what she considered to be a "huge mistake." Mrs. Vaught had spent the two previous years teaching in a preschool classroom, becoming skilled at promoting a joy of learning in a classroom that embraced a constructivist philosophy. She had learned to listen to the children and to be responsive to their needs, interests, and inquiry; encouraging children to have ownership of their learning, to try new things, and to engage freely in exploratory learning. How was Mrs. Vaught going to stay true to this teaching style, one that recognized and honored learners' ways of knowing, and meet the individual needs of her diverse class (including dual language learners and children of a wide range of abilities) without bowing to pressures that have often made kindergarten more like a primary classroom? How would the children in her kindergarten class experience a culture of joy in learning in an environment open to exploration and discovery?

Here we present learning moments illustrated through descriptions of an exploration carried out by the children and through the expressed wisdom of Mrs. Vaught as it unfolded. Informed by the concept of rich normality, we present what on the surface is a seemingly simple story. However, it is, in fact, a sample of how ordinary moments were strung together to give shape and quality to the children's experiences as they grew and transformed, individually and as a group, within the ecology of their kindergarten classroom and beyond. 
Keely D. Cline, Merlene Gilb, and Michelle Vaught

\section{Literature}

\section{The Ecology of a Classroom}

In a classroom, an ecosystem is a journey shared together. Bronfenbrenner's bioecological systems theory (Bronfenbrenner, 1979, 2005; Bronfenbrenner \& Morris, 2006) provides a meaningful framework for understanding transformational learning in a constructivist classroom. According to bioecological systems theory, a developing person is positioned within a set of nested systems that interact with one another, the most immediate of which includes settings such as family and school, and the more distant of which includes the wider community and socio-cultural context. Children are active participants in their development, influencing and being influenced by their environments. This theory acknowledges the importance of the passage of time, which may bring with it consistencies and changes.

In a constructivist classroom, each child's unique way of thinking and knowing is valued, not only as an individual, but also in relation to the other children, the teacher, the family, and the "wider world" (e.g., broader school environment, community, and greater society). Within the nested systems that are life, we, and others with whom we interact, naturally transform through interactions and shared experiences through learning that is not formally taught but evoked.

As children make connections within similar systems lived out in a classroom, ongoing and emerging opportunities for shared learning provoke problem-finding, thought, and prompt action toward making a difference in the world, or simply conveying to the "wider world" that something important is happening here. Embracing this democratic coexistence (Bronfenbrenner, 1979; Lanzi, 2011) and idea of citizenship, learning is co-constructed with others from varied and valued perspectives. Learning, in this way, is not taught but evoked. Each individual (child and adult), and the learning (practices and procedures), is transformed as a result.

\section{Relationships and Trust}

Learning happens through interactions. Theorists such as Vygotsky and Malaguzzi have long recognized that social learning emerges even before cognitive development (Gandini, 2012). Relationships are foundational in a learning community (Biermeier, 2015). Bowlby's (1973) proposal that sensitive caregiving in the context of the infant-caregiver relationship leads to a secure attachment has been extended to inform understanding of the teacher-child relationship. As viewed through this lens, children who feel emotionally secure with the teacher use the teacher as a secure base for exploring learning opportunities in the classroom (Howes \& Ritchie, 2002). Related, Erikson (1963) identified developing basic trust-reflecting a sense of faith in oneself and confidence in others-as the earliest psychosocial task in a person's development. Trust plays an essential role in teaching for transformation. To feel safe enough to reveal their true selves, including feelings and ideas, children must feel significant, accepted, and cared for within the classroom culture. Trust in the classroom emerges through meaningful interactions and relationships between both teacher and child, and between children. Children's emerging individual and group identities influence the environment and learning. 
Therefore, in a constructivist classroom, trust is at the heart of all that is transforming-the child, the teacher, as well as the learning and knowing.

\section{Rich Normality}

The concept of rich normality emphasizes the potential of everyday moments and experiences. Rich normality draws attention to the richness that can be found in all aspects of a classroom or learning environment-physical, social, emotional, and cognitive (Edwards, Gandini, \& Forman, 2012). In each of these environments, the teacher sees the significance in and gives positive attention to the "small events" (Mitchelmore \& Fleet, 2017, p. 64) and finds promise in them (Edwards et al., 2012). This promise comes in connecting these events that propel natural ways of understanding-connecting and letting the journey of learning build with children, families, and the "wider world." Resulting long-term projects are fostered in nurturing harmonious and balanced environments where children blossom emotionally, socially, and intellectually.

What follows here is a description of a project that developed over the course of several weeks in Mrs. Vaught's kindergarten classroom. This learning experience reflects the children's expressed ways of knowing captured in the rich normality of everyday moments and experiences as the project unfolded. The children's role and participation in the project is examined-individually, as a group, and in their connections to the "wider world" —-through the teacher's reflections and insights gained.

\section{The Children's Exploration: Selecting and Caring for a New Pet}

\section{Overview}

The children in Mrs. Vaught's kindergarten returned from winter break to learn that their beloved pet hedgehog, Harley, had passed away. Despite Mrs. Vaught's concerns, she found that any grief that the children were experiencing seemed overshadowed by the excitement of getting a new pet. With Mrs. Vaught's support, the children discussed and researched pet options and narrowed their list down to a leopard gecko or crested gecko. The class was part of the Horace Mann Laboratory School located on the campus of Northwest Missouri State University, and Mrs. Vaught organized a field trip to the university's science department, giving children an opportunity to learn about, hold, and interact with these types of lizards. After this field trip, the children further discussed and voted on which lizard would be best for their class, selecting a leopard gecko.

With this decision made, the children researched the needs of leopard geckos and made a shopping list of pet supplies. The time finally came for Mrs. Vaught to purchase the lizard. Thanks to Mrs. Vaught's documentation of what was unfolding on the class social media network, children's families and other teachers at the lab school were also following the class's progress. The children, as well as their "wider world" (i.e., family and lab school community), were anxious to meet the new lizard (see Figure 1)! 


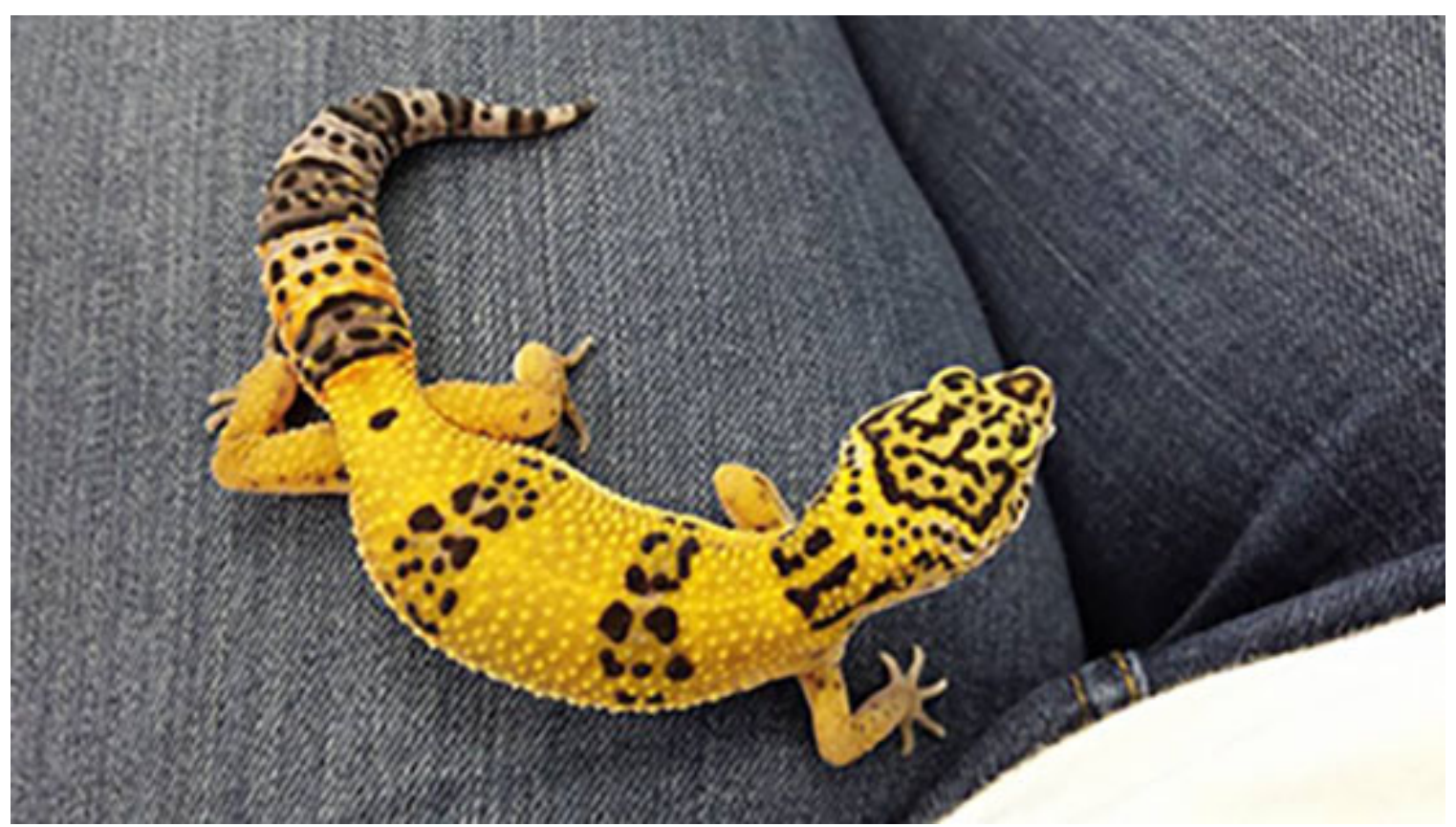

Fig. 1: The lizard, a leopard gecko, selected by the children after researching possible class pets for their kindergarten classroom.

\section{The Individual}

Meet Cylas. Cylas was the youngest child in Mrs. Vaught's kindergarten class. While he demonstrated above-average verbal and language comprehension skills, his social and fine motor skills were less developed. At times, this made it challenging for Cylas to engage with his classmates. However, as illustrated in the following description, in the context of the Mrs. Vaught's kindergarten classroom, Cylas was able to embrace his own ways of knowing and successfully engage with his peers and further establish an identity within his classroom. These same experiences simultaneously helped to build a stronger group connection among the children.

After the new lizard arrived, the children spent time getting to know her. One concern that quickly arose was that the children would tightly gather around the lizard when she was out of her cage. Mrs. Vaught called a class meeting to discuss how the class could enjoy the lizard while ensuring her safety. The children came up with the idea of using blocks to build structures for the lizard to explore while she was out of her cage. In response to the energy of the children's ideas, Mrs. Vaught supported additional opportunities to design and create structures. The children suggested adding carpet and including amenities to make the structures more comfortable, including making a small bed, toys, and even a toilet. Together, children continued to modify the designs and features of their structures, which grew in complexity over time.

One morning, Cylas, working independently, which was often his preference, initiated building a new rectangular structure for the lizard. Mrs. Vaught joined Cylas in a conversation about the structure, suggesting he build on to it. Cylas came up with the idea of building a lizard maze, and he then excitedly announced this to the class. Many children asked Cylas if they could help build the maze, and Cylas 
accepted their requests. Cylas served as the director of the maze construction, providing leadership as decisions were made about the design.

In the past, if a large group of children joined him, Cylas would often become overwhelmed and leave the group or become overexcited and tear down group efforts, rather than work cooperatively. In this instance, neither happened. Rather, Cylas shined as a leader, using his excellent verbal skills to direct his friends in designing and creating the maze (see Figure 2).

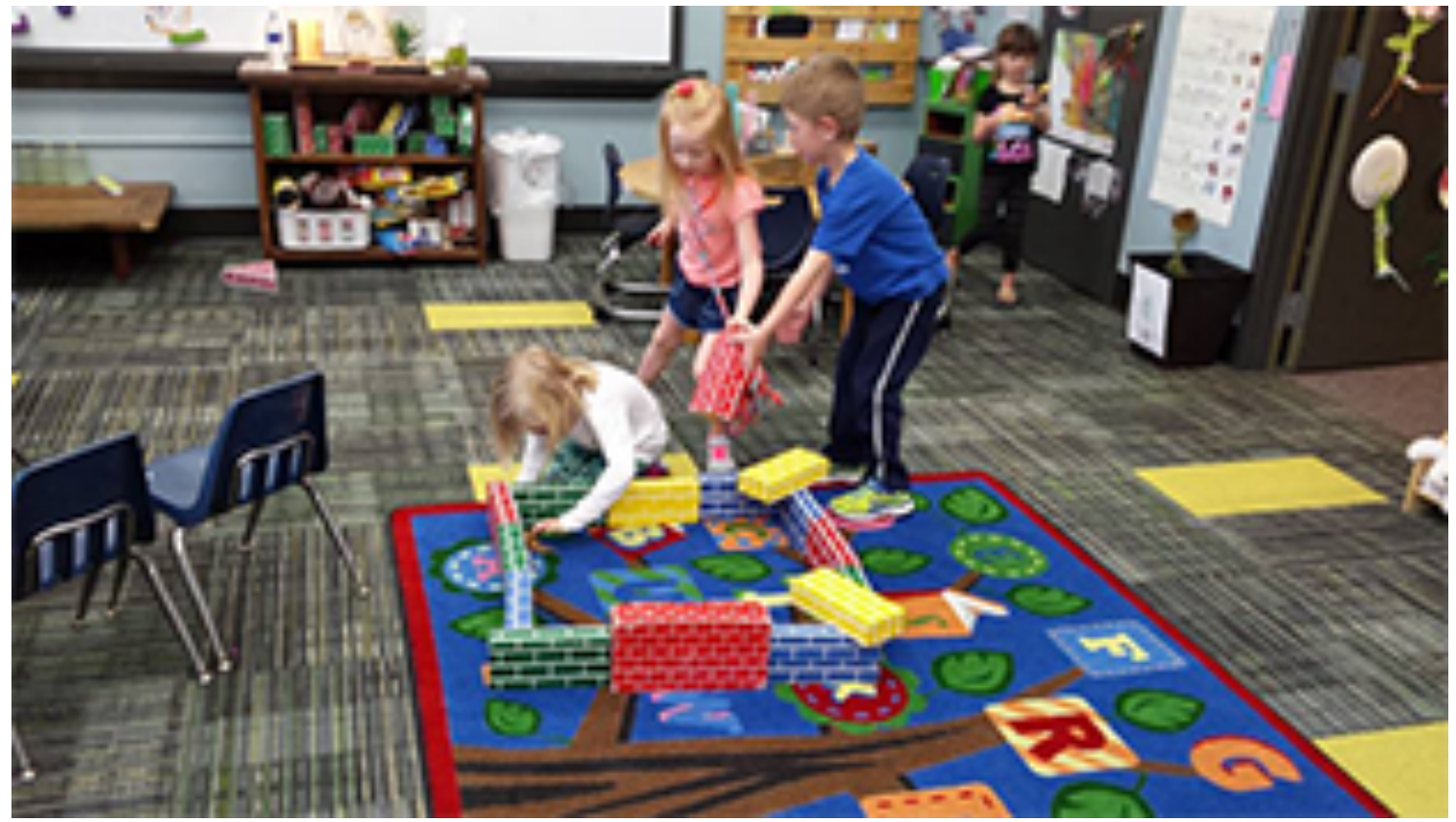

Fig. 2: Cylas shines as a leader, serving as the director as a maze is constructed for the pet lizard.

\section{Mrs. Vaught's Wisdom: Focusing on the Individual}

Each child has the right to be respected for his or her uniqueness and extraordinary potential, manifested in distinct "rhythms of growth and development" (Rinaldi, 2013, p. 31). This is at the heart of Mrs. Vaught's classroom culture and intentional in her daily practice. Learning is a social experience, and each child plays a unique role in a community of learners. Accepting that a child is capable and can become confident to think, share ideas, and work with others—unique to the child's strengths—allows us to see each child not simply for what they can do, but for who they are. In the case of Cylas, he was accepted for who he was (and who he was becoming) as an individual, as well as who he was in the company of others. By focusing on each individual child and his or her nuanced ways of knowing and making sense of their world, Mrs. Vaught was able to understand and support the individual children's needs as part of a diverse group of learners. She fostered an inclusive and equitable learning environment, one that recognized the special rights of all children and the unique and unrepeatable qualities each child brings to the collective learning and culture of a classroom (Dahlberg \& Moss, 2006). Below are reflections and insights Mrs. Vaught gained in examining the role of the individual child in the project as it unfolded (see Figure 3). 


\section{Considerations for Focusing on the Individual}

1. Dedicate time to getting to know and respect each child's uniqueness, including his/her uniquely expressed ways of knowing, and allow each child to be his/her true self.

2. Be aware of the individual child's response to the environment (objects, situations, materials, etc.) in the flow of the day. Note his/her decisions and contributions as a way of expressing who they are and how they learn.

3. Recognize that the child is both a human "being" in the here-and-now, as well as someone on a path to "becoming" his/ her future self. Meet the child where he/she is and provide opportunities for growth and development.

4. Focus on the "real" not the "ideal" child.

5. Work to reframe what might be considered "issues." When understood (by the child, other children, and teacher), these "issues" can be seen as forms of diversity among children, valuable to the process of learning.

6. With this reframed understanding (i.e., seeing diversity rather than "issues") in mind, help each child find his/her voice and to see that this voice is heard and honored in the community of learners.

Fig. 3: Considerations for teachers when focusing on the individual child in project work.

\section{The Group}

Returning to the children's maze-building, once the children were happy with the structure (see Figure 4), the lizard was given a chance to explore. The children now had a new problemthe lizard was not as excited to go through the maze as the children were for her to go through it. Gathered around the maze, the children generated and tested ideas about how to coax the lizard through the maze (see Figure 5). Sofiya blocked the lizard's way so she couldn't go back into the original rectangular structure. The lizard's only choice would now be to go into the maze. Tavian grabbed a mealworm to see if food would motivate the lizard. Neither of these attempts were successful in getting the lizard to move. Then, Elley started gently touching the lizard's tail to encourage her to move through the maze. The children found that this was effective and excitedly cheered. However, the children quickly realized that when they yelled or cheered, or if more than one person touched the lizard's tale at once, the lizard totally stopped moving. The children decided that they needed to be quieter to avoid scaring the lizard and that they would need to take turns "helping" the lizard through the maze. Negotiations continued, as did the exchange of ideas and solutions, much like the give-and-take of a family discussion.

For the next few weeks, Mrs. Vaught, recognizing the children's ways of exploration and the project that was forming, documented the learning journey. As a way of supporting the ideas originated by the children, she made a variety of blocks and open-ended materials available. Mrs. Vaught provoked the children's deeper inquiry, problem solving, and creativity through her questions and conversation as she, too, was part of the learning. The children, in turn, enthusiastically initiated constructing multiple configurations of the maze in a joyful exchange. 


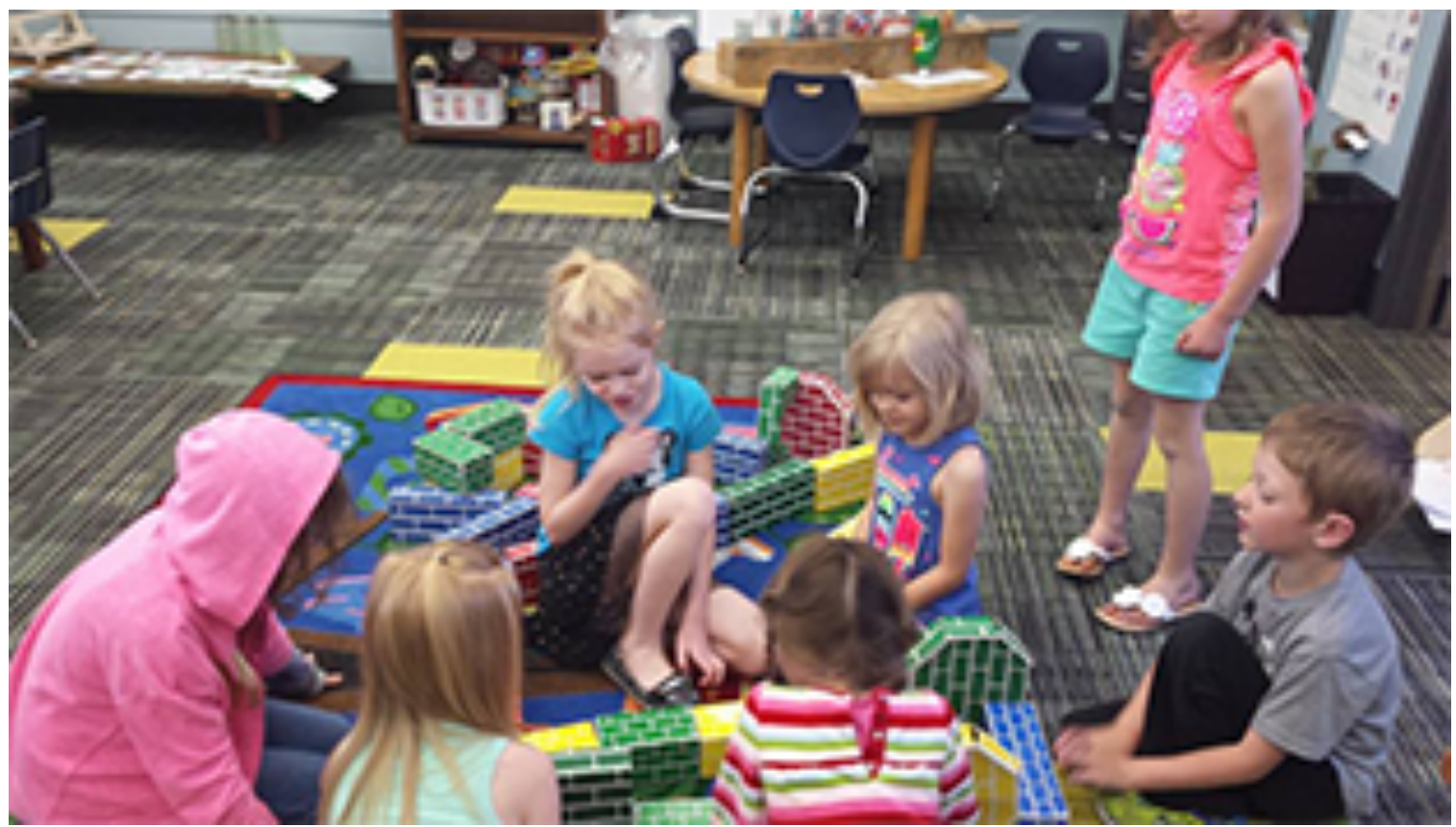

Fig. 4: A group of children negotiating configurations of the maze for the lizard.

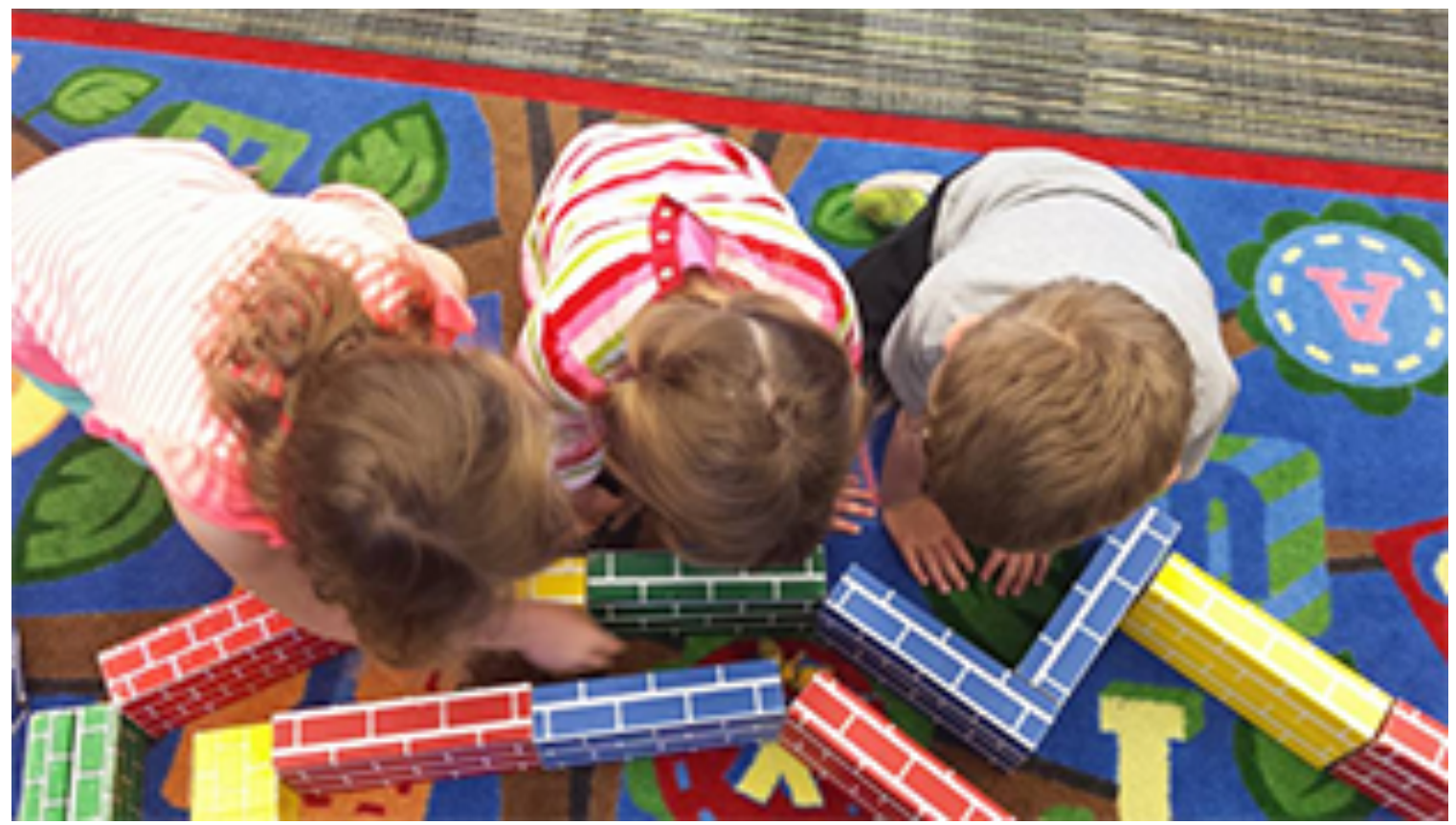

Fig. 5: The children work together to generate and test ideas about how to coax their pet lizard through the maze. 


\section{Mrs. Vaught's Wisdom: Focus on the Group}

When a group forms in the learning process, something new is created. The idea of the teacher as the giver of knowledge is replaced with the freedom of ideas and a flow of learning co-constructed with the children, embracing the chaos that results from children's engagement in self-directed exploration with open-ended materials. Children are empowered as thinkers, contributing and collaborating with other points of view. These exchanges allow for children to develop authentic friendships reflected in caring, careful communication, and an openness to others, facilitated in a context that lends itself to inquiry, problem solving, and group interactions (Hong, Shaffer, \& Han, 2016). The teacher becomes an active partner in the learning process - a keen observer of children's learning for the purpose of identifying paths to guide further exploration in an environment where children work cooperatively toward common goals. In this story, as relationships drove the learning, there was a genuine respect for other children's ways of knowing and an acceptance of the thoughts and ideas of others. Mrs. Vaught viewed her classroom as a family of learners, formed in a culture of trust and the shared enjoyment in the give-and-take of being together. Below are reflections and insights Mrs. Vaught gained in examining the role of group work in the project as it unfolded (see Figure 6).

\section{Considerations for Focusing on the Group}

1. Embrace the concept of co-construction in teaching and learning, a concept that may get "lost" in the demands and culture in elementary classrooms. Refrain from being the giver of knowledge or solutions. Rather, respect and honor children's ways of knowing and coconstruct meaning with them. Discuss problems, generate ideas, and find solutions together.

2. Provide access to open-ended materials as a way of enhancing shared interest, discovery, flexible thinking, and initiative between the children.

3. Provide freedom in the flow of learning; embrace and find joy in the "organized chaos" of group exploration.

4. Encourage the rhythm and repetition of groups as they form and re-form throughout project work, and archive a memory of this learning. What children learn how to do together today, they know how to do together tomorrow and beyond, strengthening their sense of togetherness and belonging.

5. Drawing from the concept of "rich normality," find the creative possibilities in everyday moments in the life of a classroom. What seems ordinary can become extraordinary in the formation of projects.

6. Promote a sense of family in the classroom. Engaging in give-and-take within the context of a warm and emotionally supportive context inspires cooperation, and allows meaningful interactions to blossom.

Fig. 6: Considerations for teachers when focusing on children working in groups in project work.

\section{The "Wider World"}

Once Mrs. Vaught's kindergarten class had their new pet, the lizard needed a name. The class had explored the concept of elections earlier in the fall after demonstrating interest in this topic as the presidential, state, and local campaigns were underway. These explorations included walking around the surrounding residential neighborhood, examining political signs in yards, as well as discussing the concept of voting. The class members applied their knowledge of elections to help determine a name for their lizard. 
First, the class talked about possible names, generating a list of about 25 names. The class voted, narrowing the list down to four top choices: Poppy, Godzilla, Ella, and Valentine. Children discussed how to proceed, voicing that they wanted their families to be involved in making the important decision. This then turned into a discussion of inviting members of the children's "wider world" (e.g., grandparents, the entire lab school) to participate. Together, the children created a plan to engage others in the decision-making. The class set up a ballot box in the hallway outside of their classroom (see Figure 7). Children made posters inviting participation in the voting and hung them on the walls where the lab school community (e.g., other elementary students, teachers, university professors from the same university as the lab school, practicum students) could see them (see Figures 8 and 9). Children frequently invited others-children and adults-to come vote if they met them in the hall of the lab school.

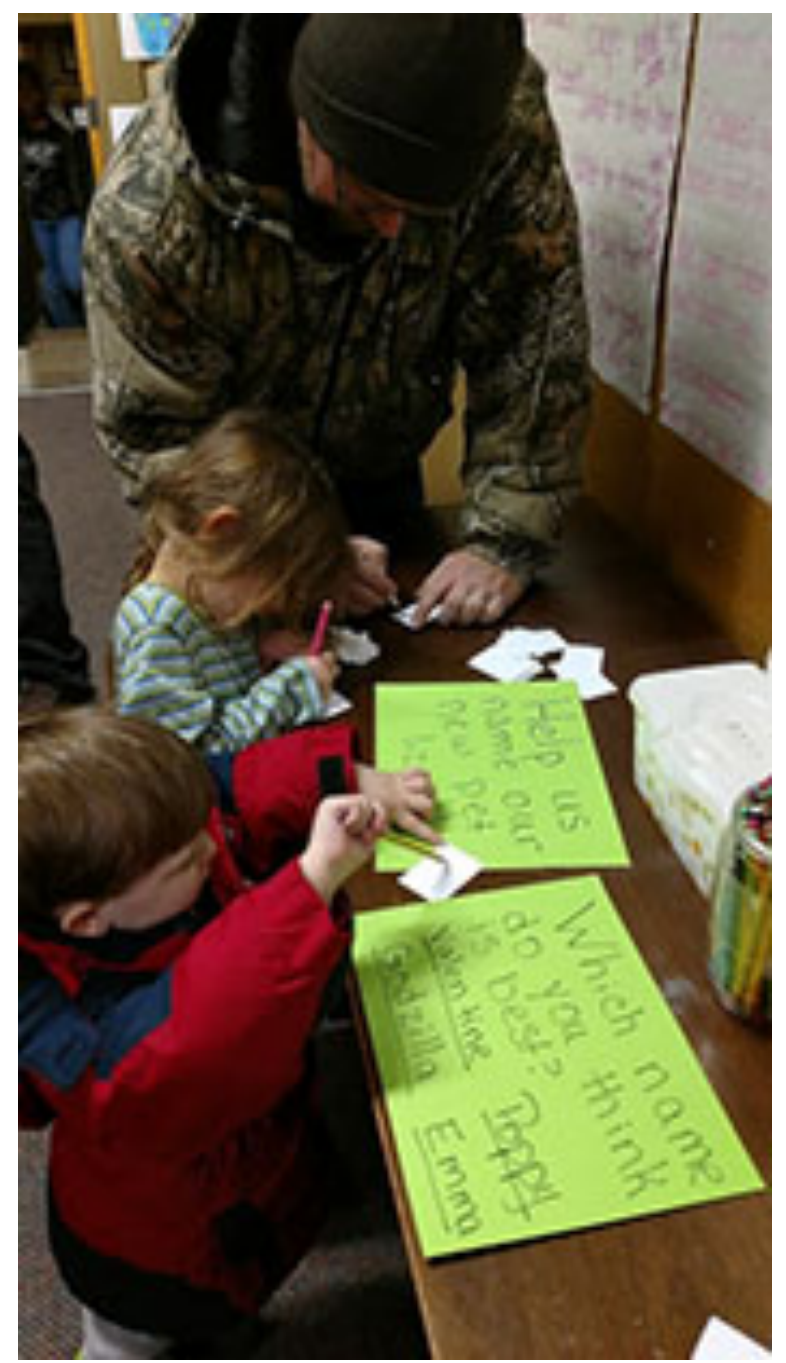

Fig. 7: The ballot box in the hallway directed the school community to vote,

including listing the suggested pet names from the children. Here a kindergarten child casts a vote with her father and younger brother. 


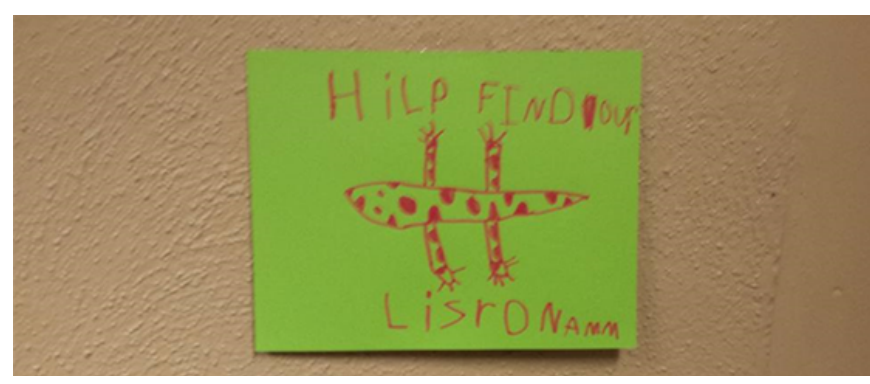

Fig. 8: The children invite the school community to vote on the pet lizard's name by posting signs on the walls around the building. This sign reads, "Help find our lizard [a] name."

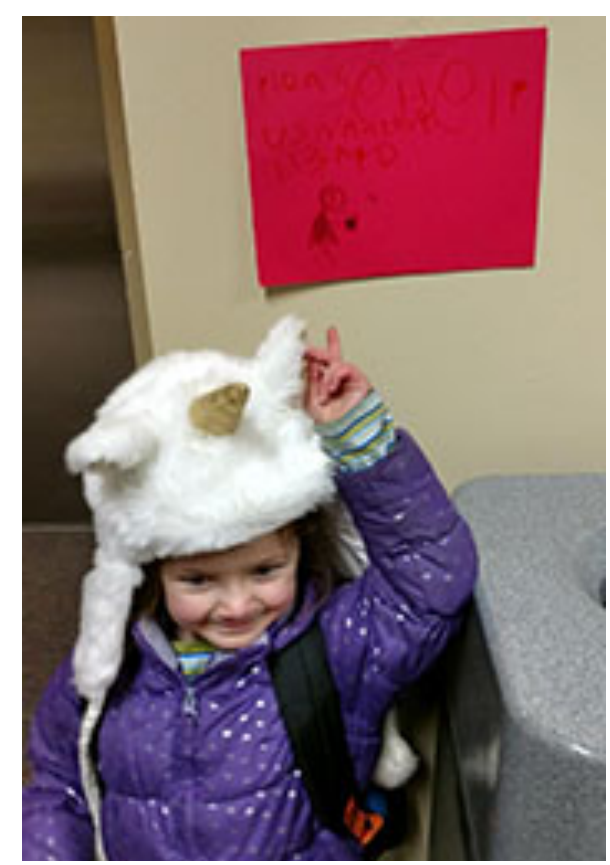

Fig. 9: A child proudly points to the sign she made to encourage the school community to participate in voting on the name of the class's pet lizard.

The children's enthusiasm about their voting project seemed contagious, spreading to the entire lab school community. There was a great deal of activity around the ballot box, and it seemed like the whole lab school was talking about the pet lizard and what her name would be. Mrs. Vaught also promoted the election through her documentation of the learning on the class's social media network, extending the voting opportunity to individuals who may not have been physically at the lab school on a regular basis. Family members posted comments to the page, asking if votes had been counted or if the name had been selected.

The class members' efforts to involve their "wider world" were far-reaching, exceeding the expectations of Mrs. Vaught and the children. When the time came to open the ballot box, the children were so excited that some were literally crawling into Mrs. Vaught's lap to get a closer look. Tallying the votes was full of suspense (see Figure 10). The class even found that there were some "write in" suggestions, including the name "Tractor" by the younger brother of one kindergarten child. The class, including the children who had voted for a different name, were pleased to learn that the name "Poppy" had received the most votes. The children invited members of the lab school community to come and meet their newly named pet. Mrs. Vaught also announced the pet's name on the class's social media network, and this announcement was met with many reactions and comments. 


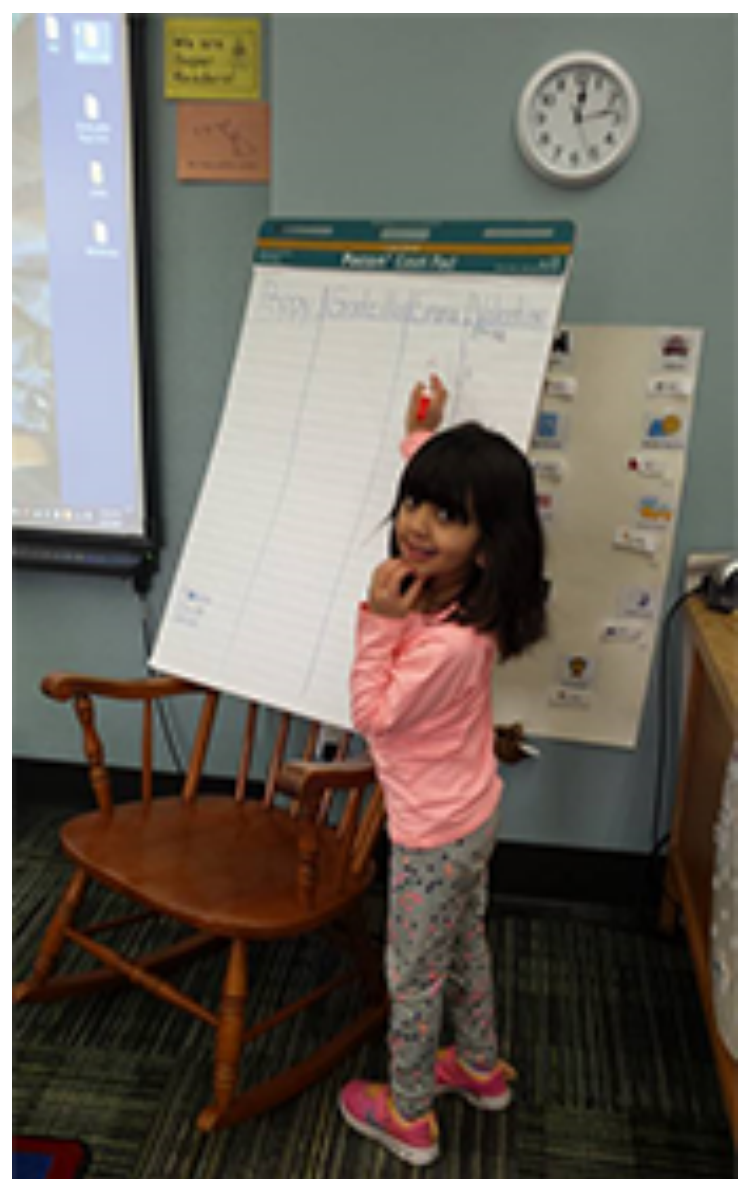

Fig. 10: The children take turns tallying the votes to determine their pet lizard's name.

\section{Mrs. Vaught's Wisdom: Focus on the "Wider World"}

The world today, even to a young child, is more closely connected than ever before. In these learning moments, the exchange of information and resources that contribute to learning was both drawn into and extended beyond the classroom to the children's community and their families. These broader connections to a "wider world" not only informed others of the happenings within the classroom, but also invited the contributions that helped to transform the children's learning and project outcome through a bidirectional exchange. As a result of Mrs. Vaught sharing the learning journey through her documentation, everyone was drawn into the energy and anticipation of what was unfolding, or in other words, transforming. Emotional connections were sparked, and there was shared excitement and emotion surrounding the learning project. The children actively co-constructed their knowledge, identity, and culture in relation to others and the world (Dahlberg, Moss, \& Pence, 2007). The children's project, now a part of their "identity," became "seen" in their lab school and community (their "wider world"), growing an understanding of and respect for children's unique ways of knowing. The culture of childhood and of learning was made visible, and the children were witness to this emergence. Below are reflections and insights Mrs. Vaught gained in examining the role of the children's connections to their "wider world" in the project as it unfolded (see Figure 11). 


\section{Considerations for Focusing on the "Wider World"}

1. Support the children in forming a group identity and in giving them opportunities to communicate that identity within the school and wider community.

2. Help children see their possibility and participation in the "wider world." Trust the connections children make between relationships (academic and social) formed within and those that extend beyond the classroom walls. The smallest connections make for a more faceted bigger picture.

3. Make the classroom an inviting place for members of the "wider world" to visit, and help children to see that others are interested and invested in their efforts by providing opportunities to interact and communicate with the "wider world." Embrace the energy of ideas as they flow (bidirectionally) from and into the classroom. Provide ways for children to share and for the class to draw in perspectives and participation from the "wider world" in the learning process.

4. Develop a process and habit of documenting learning. Make the documentation accessible, not only for the children, but also to their "wider world." Documentation offers visible evidence of the different ways of knowing and expressing thinking and learning for all to revisit, reflect on, and take joy in.

5. Embrace the role of emotion in learning (now and lifelong). Recognize that emotion is evoked in relation with others and gives children power over their learning and how their knowing is expressed.

6. Recognize the power of transformational learning. When you let go of the need to control the direction and final outcome of a project, the children may take learning to places you could not have anticipated.

Fig. 11: Considerations for teachers when focusing on the children's "wider world" in project work.

\section{Conclusion}

On the surface, this is a seemingly simple story about selecting and naming a class pet. However, importantly, the events described here reflect a deeper, more complex narrative of transformation that spanned, not only throughout this project, but also across the year of kindergarten in Mrs. Vaught's classroom. Mrs. Vaught started the school year concerned about her own transition from teaching preschool to teaching kindergarten. How was she going to stay true to the teaching style in which she believed, making sure to meet the needs of her diverse class of learners, without bowing to pressures that have often made kindergarten more like a primary classroom? How would the children in her kindergarten class experience a culture of joy in learning in an environment open to exploration and discovery?

It was, in part, through the processes of building trust and a continuing dedication to teaching for transformation that Mrs. Vaught found the answer to these questions. Though she initially doubted herself, Mrs. Vaught faced this new challenge and found freedom and acceptance through coming to trust in her own attunement to children's way of knowing. Capturing the promise found in the rich normality of everyday moments lived out in the classroom, Mrs. Vaught cultivated an inclusive and equitable classroom culture-a true family of learners. She helped the children develop trust in themselves (through embracing their own unique ways of knowing), each other (through harmonized 
Honoring Children's Ways of Knowing: A Story of Trust and Transformation in a Kindergarten Classroom

and balanced group experiences), and the "wider world" around them. In doing so, Mrs. Vaught set the stage for a year of transformational learning, filled with exploration and discovery, for all. Each member of the learning community-children, teacher, families, and wider community-transformed. These experiences will forever touch the lives of those involved, because when something transforms it is changed, never returning to what it previously was.

\section{References}

Biermeier, M. A. (2015). Inspired by Reggio Emilia: Emergent curriculum in relationship-driven learning environments. Young Children, 70(5), 72-73.

Bowlby, J. (1973). Attachment and loss: Vol. 1. Attachment. New York, NY: Basic Books.

Bronfenbrenner, U. (1979). The ecology of human development: Experiments by nature and design. Cambridge, MA: Harvard University Press.

Bronfenbrenner, U. (2005). The bioecological theory of human development. In U. Bronfenbrenner (Ed.), Making human beings human: Bioecological perspectives on human development (pp. 3-15). Thousand Oaks, CA: Sage.

Bronfenbrenner, U., \& Morris (2006). The bioecological model of human development (Vol. 1, pp. 793-828). Hoboken, NJ: John Wiley.

Cooper, M. (2012). Is beauty a way of knowing? In C. Edwards, L. Gandini, \& G. Forman (Eds.), The hundred languages of children: The Reggio Emilia experience in transformation (pp. 295-302). Santa Barbara, CA: Praeger.

Cutler, K., \& McKillip, A. (2017). An innovative collaborative design project: Exploring the aesthetic dimensions of Reggio-inspired furniture. Innovations in Early Education: The International Reggio Emilia Exchange, 24(2), 24-37.

Dahlberg, G., \& Moss, P. (2006). Introduction: Our Reggio Emilia. In C. Rinaldi, In dialogue with Reggio Emilia: Listening, researching, and learning. London: Routledge.

Dahlberg, G., Moss, P., \& Pence, A. (2007). Beyond quality in early childhood education and care: Postmodern perspectives (2nd ed.). New York, NY: Routledge.

Edwards, C. P., Gandini, L., \& Forman, G. E. (2012). The hundred languages of children: The Reggio Emilia experience in transformation. Santa Barbara, CA: Praeger.

Erikson, E. H. (1963). Childhood and society (2nd ed.). New York, NY: Norton.

Gandini, L. (2012). History, ideas, and basic principles: An interview with Loris Malaguzzi. In C.P. Edwards, L. Gandini, \& G.E. Forman (Eds.), The hundred languages of children: The Reggio Emilia experience in transformation, 3rd ed. (pp. 27-71). Santa Barbara, CA: Praeger.

Hong, S. B., Shaffer, L., \& Han, J. (2016). Reggio Emilia inspired learning groups: Relationships, communication, cognition, and play. Early Childhood Education Journal, 44(1), 1-11.

Howes, C., \& Ritchie, S. (2002). A matter of trust: Connecting teachers and learners in the early childhood classroom. New York, NY: Teachers College Press. 
Lanzi, D. (2011, October). The values of the Reggio Emilia educational project. Paper session presented at the North American Study Group, Reggio Children, Reggio Emilia, Italy.

Mitchelmore, S., \& Fleet, A. (2017). The worlds of the very young: Seeing the everyday in small pieces. In A. Fleet, C., Patterson, \& J. Robertson (Eds.), Pedagogical documentation in early years practice: Seeing through multiple perspectives (pp. 61-72). London: SAGE.

Rinaldi, C. (2013). Re-imagining childhood: The inspiration of Reggio Emilia education principles in South Australia. Government of South Australia. Retrieved from https://www.education.sa.gov.au/sites/g/files/net691/f/reimagining-childhood.pdf

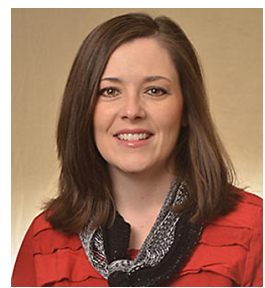

Keely D. Cline, PhD, is an Assistant Professor of Psychology in the School of Health Science and Wellness, Division of Behavioral Sciences, at Northwest Missouri State University. Her professional and research interests include building supportive contexts for child development, including through parent-child relationships and early childhood classrooms. She is interested in cultural studies and progressive educational practices from the international community. Among her publications are ones that have focused on parent-child shared book reading among Early Head Start families, and the language and literacy environment at Filastrocca, an Italian preschool that has a special mission focused on books, stories, and the imagination.

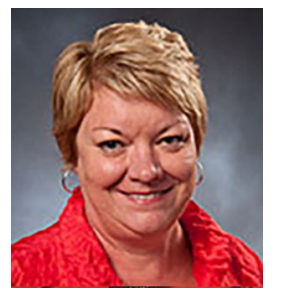

Merlene Gilb, Ed. D., is an Assistant Professor in the School of Education at Saint Louis University. Her experience in education spans over 30 years and includes work in school administration, curriculum development, professional development, gifted education, and teaching at the preschool, elementary, and university level. A student of the Reggio Emilia Approach, she has visited Reggio Emilia, Italy several times as a participant in the U.S. Student and Professor Study Group. Her professional and research interests include teacher learning, leadership, and research; leading for change by inspiring innovative practice; and responsive curriculum design and models.

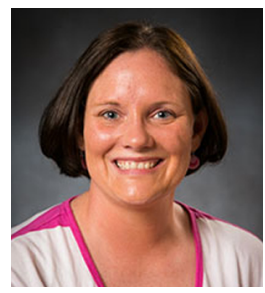

Michelle Vaught, M.S.Ed., is a teacher at the NAEYC-accredited Leet Center Preschool located on Northwest Missouri State University's (NWMSU) campus. She is also an adjunct faculty member for the university. Previous experiences include being a kindergarten teacher at the Horace Mann Laboratory School at NWMSU and an early childhood and elementary special education teacher. Michelle's professional interests include Reggio-inspired teaching strategies (has traveled to Reggio Emilia and participated in a U.S. Student and Professor Study Group), interest-based teaching strategies, social justice within the early childhood classroom, the roles of families within classrooms, and connecting the learning of theory and practice for practicum students. 